\title{
Postoperative analgesic effect of parecoxib sodium local anesthesia in patients with breast cancer through systematic review and meta-analysis
}

\author{
Fangfang Chen, Yangfan Fan, Saisa Zhu \\ Department of Surgery, Women's Hospital, Zhejiang University School of Medicine, Hangzhou, China \\ Contributions: (I) Conception and design: F Chen, S Zhu; (II) Administrative support: Y Fan; (III) Provision of study materials or patients: F Chen, Y \\ Fan; (IV) Collection and assembly of data: All authors; (V) Data analysis and interpretation: All authors; (VI) Manuscript writing: All authors; (VII) \\ Final approval of manuscript: All authors. \\ Correspondence to: Fangfang Chen. Department of Surgery, Women's Hospital, Zhejiang University School of Medicine, No. 555, Zhongshan Middle \\ Road, Shangcheng, Hangzhou 310000, China. Email: ffchen2014@zju.edu.cn.
}

Background: Postoperative pain can seriously affect a patient's recovery, and parecoxib sodium has a good
analgesic effect. However, there is a lack of clinically systematic analyses of the effects of parecoxib sodium
on postoperative pain in breast cancer patients. The aim of the present study was to systematically evaluate
the efficacy and safety of parecoxib sodium local anesthesia in the treatment of postoperative pain in breast
cancer patients. Methods: Literature published from January 2010 to December 2020 was searched in the China National Knowledge Infrastructure database, Wanfang database, PubMed, and Cochrane Library. Literature on randomized controlled trials of parecoxib sodium local anesthesia in patients with breast cancer was collected. Method of treatment was extracted and literature quality was assessed. Meta-analyses of included literature were performed using RevMan 5.3.

Results: A total of 17 randomized controlled trials were included, with a total of 1,032 breast cancer surgery patients. The experimental group was treated with parecoxib sodium anesthesia, and the control group was treated with other anesthesia methods. The meta-analysis results showed that there were obvious differences among visual analogue scale (VAS) score of the experimental group and control group $2 \mathrm{~h}$ after surgery [mean difference (MD): $-0.79 ; 95 \%$ confidence interval (CI): -1.29 to $-0.29 ; \mathrm{P}=0.002], 4$ h $(\mathrm{MD}=-0.77 ; 95 \%$ CI: $=-1.51$ to $-0.03 ; \mathrm{P}=0.04), 6 \mathrm{~h}(\mathrm{MD}:-1.10 ; 95 \% \mathrm{CI}:-1.41$ to $-0.80 ; \mathrm{P}<0.00001), 8 \mathrm{~h}(\mathrm{MD}:-0.66 ; 95 \%$ CI: -1.00 to $-0.33 ; \mathrm{P}=0.0001), 12$ h (MD: $-0.92 ; 95 \% \mathrm{CI}:-1.24$ to $-0.60 ; \mathrm{P}<0.00001), 24$ h (MD: -0.86 ; $95 \%$ CI: -1.15 to $-0.58 ; \mathrm{P}<0.00001)$, and $48 \mathrm{~h}$ (MD: $-0.90 ; 95 \% \mathrm{CI}:-1.47$ to $-0.33 ; \mathrm{P}=0.002$ ). Moreover, visual analog scale score and the postoperative controlled analgesia frequency of patients in the experimental group (MD: -2.08 ; $95 \% \mathrm{CI}:-2.88$ to $-1.27 ; \mathrm{P}<0.00001$ ) and the incidence of adverse reactions (odds ratio: $0.52 ; 95 \% \mathrm{CI}$ : $0.34-0.80 ; \mathrm{P}=0.002)$ were significantly reduced.

Discussion: Parecoxib sodium local anesthesia for breast cancer patients has good postoperative analgesia and treatment safety.

Keywords: Parecoxib sodium; breast cancer; surgery; postoperative analgesia; meta-analysis

Submitted Aug 23, 2021. Accepted for publication Sep 29, 2021.

doi: $10.21037 /$ gs-21-632

View this article at: https://dx.doi.org/10.21037/gs-21-632 


\section{Introduction}

In recent years, the incidence of breast cancer among females has shown an increasing trend year by year, seriously threatening the life and health of women. At present, surgery is still the main method for the treatment of breast cancer. Pain after surgery is caused by the damage of muscle, soft tissue, or bone during the operation (1). Post-mastectomy pain syndrome accounts for a certain proportion of postoperative patients with breast cancer. Post-mastectomy pain syndrome is likely to occur in breast cancer patients at a younger age and with preoperative psychological abnormalities. If the postoperative pain is not handled properly, it will seriously affect the patient's recovery effect, and causes problems, such as prolonged hospitalization, increased medical expenses, and reduced patient quality of life. The most commonly used postoperative analgesia are opioids. The combination of dexmedetomidine and sufentanil can effectively improve postoperative pain symptoms of breast cancer patients, and the combination of these has little effect on postoperative adverse reactions, such as chills and vital signs. Although opioids have ideal analgesic effects, they can cause adverse reactions, such as nausea and vomiting, respiratory depression, and drug dependence $(2,3)$.

Parecoxib sodium is a highly selective cyclooxygenase 2 inhibitor administered by intravenous or intramuscular injection. It has the advantages of a low adverse reaction rate, little impact on organ function, and reduced incidence of adverse cardiovascular events (4). As one of the most commonly used injectable drugs in clinical practice, parecoxib sodium can inhibit the synthesis and release of prostaglandins in the body, thereby exerting an analgesic effect (5). Parecoxib sodium is often used in the short-term treatment of pain in patients after surgery. However, some scholars have applied parecoxib sodium before and after surgery and found that it can also significantly improve the pain problem of postoperative patients. Studies have shown that the analgesic effect of intravenous injection of $40 \mathrm{mg}$ parecoxib sodium at the time of anesthesia induction is better than before the end of surgery, showing an advanced analgesic effect (6). The advanced application of parecoxib sodium in gynecological surgery can reduce the amount of postoperative fentanyl and improve the quality of analgesia. In addition, it has been noted that parecoxib is a safe and effective drug for perioperative analgesia (7).

At present, there are many systematic evaluation studies on parecoxib sodium for postoperative analgesia in patients, but the indicators included in the analysis are not comprehensive enough. At the same time, there is no research to systematically evaluate the effect of parecoxib sodium on postoperative analgesia in breast cancer patients. Therefore, there is currently a lack of systematic evaluations of the efficacy of parecoxib sodium for postoperative pain in patients undergoing breast cancer surgery. Therefore, in the present study, literature on the curative effect of parecoxib sodium in the treatment of postoperative pain in breast cancer patients was searched and meta-analyses were performed to provide guidance for the establishment of personalized and rational analgesia for breast cancer patients. We present the following article in accordance with the PRISMA reporting checklist (available at https:// dx.doi.org/10.21037/gs-21-632).

\section{Methods}

\section{Literature search}

Randomized controlled trials published from January 2010 to December 2020 in the China National Knowledge Infrastructure database, Wanfang database, Wanfang medical database, VIP database, PubMed, Cochrane Library, and Web of Science were systematically searched. Preliminary literature retrieval was performed using the keywords "parecoxib sodium" and "breast cancer", followed by a secondary retrieval using the keyword "analgesia".

\section{Inclusion and exclusion criteria}

The inclusion criteria were as follows: (I) randomized controlled trials, including single-blind, double-blind, and non-blind research; (II) the trial group's intervention was parecoxib sodium anesthesia, and other anesthesia methods for the control group is; and (III) patients diagnosed with breast cancer and undergoing surgical treatment, and classified as class I or II according to the American Association of Anesthesiologists (ASA).

The exclusion criteria were as follows: (I) patients with a history of ischemic heart disease, cerebrovascular disease, or peripheral arterial disease; (II) patients with a history of asthma; (III) patients who have used opioid or non-opioid analgesics for a long period of time; (IV) non-original research reports, including review research, meta-analysis research, and treatment experience summary research; (V) case report research or animal experiment research; (VI) studies with no research control group or in which the 
samples between groups were not comparable; and (VII) incomplete patient information and data results.

Three experts in the field read and screened the literature that met the selection requirements. The title and abstract of each article were read carefully, and literature that did not meet the inclusion criteria were excluded. The full text of the literature was then reviewed to determine if the article met the criteria and would be included in the present study.

\section{Quality evaluation}

The literature quality of the included studies was evaluated according to the quality evaluation method recommended by Cochrane System Reviewer Manual 5.1.0 (China Evidence-Based Medicine/Cochrane Center). The evaluation items included the following: (I) an explanation of the generation method of random sequence; (II) a hidden distribution method; (III) blinding; (IV) data incompleteness bias; (V) selective reports of the results of the study; and (VI) other potential biases in the study.

The revised Jadad Quality Assessment Scale was used to evaluate the literature quality of the included studies. The evaluation items included the following: (I) a specific method of grouping; (II) a hidden method of randomization; (III) implementation of the double-blind method; and (IV) patients who were lost to follow up or withdrew during the study. The Jadad Quality Assessment Scale evaluation score was obtained by adding the scores of the above 4 items. A score of 1-3 was regarded as a low-quality literature, and a score of 4-7 was regarded as a high-quality literature.

\section{Observation indicators}

Observation indicators were as follows: (I) visual analog scale (VAS) at different time points after surgery (total score was $0-10$ points). A score of 0 indicated no pain; a score of 1-3 indicated mild pain that the patient could tolerate; a score of 4-6 indicates moderated pain that could affect the patient's sleep status, but could tolerated; and a score of 7-10 indicated severe and unbearable pain; (II) the number of times that patients received patient controlled analgesia (PCA) after surgery; and (III) the probability of adverse reactions, such as respiratory depression, nausea and vomiting, and dizziness in patients after surgery.

\section{Statistical analysis}

RevMan 5.3 (International Cochrane Collaboration
Network) was used for the data meta-analysis. An appropriate analysis model was selected based on the heterogeneity analysis results of the data. Analysis was performed using the random-effects model (REM) when $\mathrm{I}^{2}>50 \%$, which suggested heterogeneity of studies, and the fixed-effects model when $\mathrm{I}^{2} \leq 50 \%$, which indicated no heterogeneity. Therefore, this research uses different models to analyze the same data, and conducts sensitivity analysis by comparing the estimates of combined effect values and interval differences. For continuous variable data, statistical results were presented as mean difference (MD) and $95 \%$ confidence interval (CI) if a unified measurement method was used. If there was not a unified measurement method, the results were presented as standard MD and $95 \%$ CI. For measurement data, statistical results were presented as odds ratio (OR) and 95\% CI if a unified measurement method was adopted. Otherwise, they were presented as relative risk and $95 \%$ CI. The publication bias of literature was qualitatively analyzed using the funnel chart of RevMan 5.3. $\mathrm{P}<0.05$ indicated statistical significance.

\section{Results}

\section{Search and screening results}

A preliminary 288 articles were obtained through various electronic databases, and the literature was imported into NoteExpress Literature management software (Beijing Aegean Software Company) for preliminary screening to removal of duplicate literatures. After the titles and abstracts of literature were read, those that did not meet the inclusion criteria were excluded, such as reviews, meta-analyses, and animal trials. After the full text of the literature was read, those that did not meet the inclusion criteria were excluded, such as summaries of treatment experience and individual case reports. Finally, a total of 17 studies were included and 1,032 breast cancer patients involved (8-24). All of these studies were randomized controlled trials of parecoxib sodium anesthesia for postoperative pain in breast cancer patients. Figure 1 shows the screening process.

\section{Basic characteristics of the included articles}

All of the included studies reported the study type, sample size, type of surgery, breast tumor grade, anesthesia method, and observation indicators. The basic features included are shown in Table 1. 


\section{Identification of studies via databases and registers}

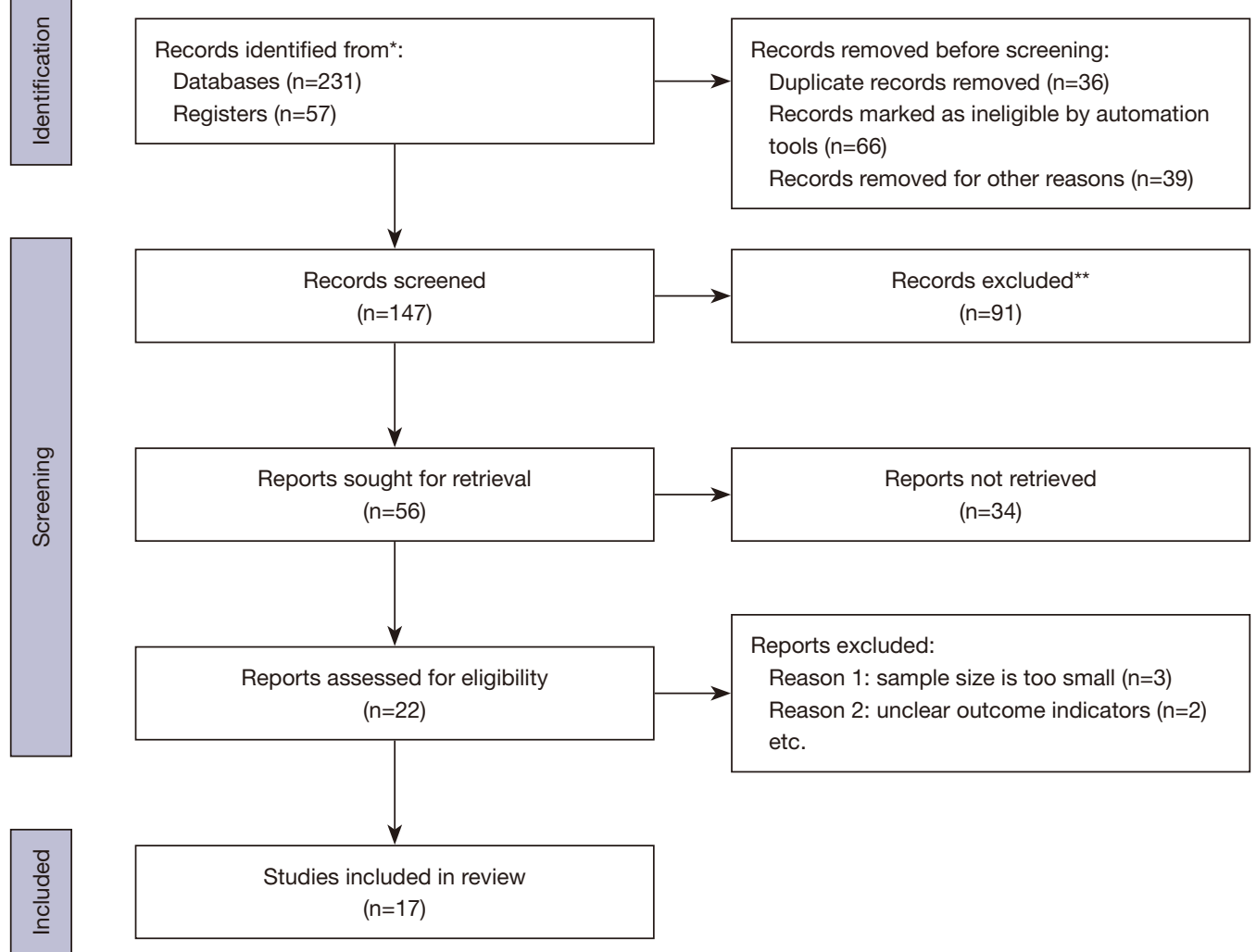

Figure 1 Search flowchart of literature included in the meta-analysis. *, consider, if feasible to do so, reporting the number of records identified from each database or register searched (rather than the total number across all databases/registers); ${ }^{* *}$, if automation tools were used, indicate how many records were excluded by a human and how many were excluded by automation tools.

Table 1 Basic characteristics of the included literature

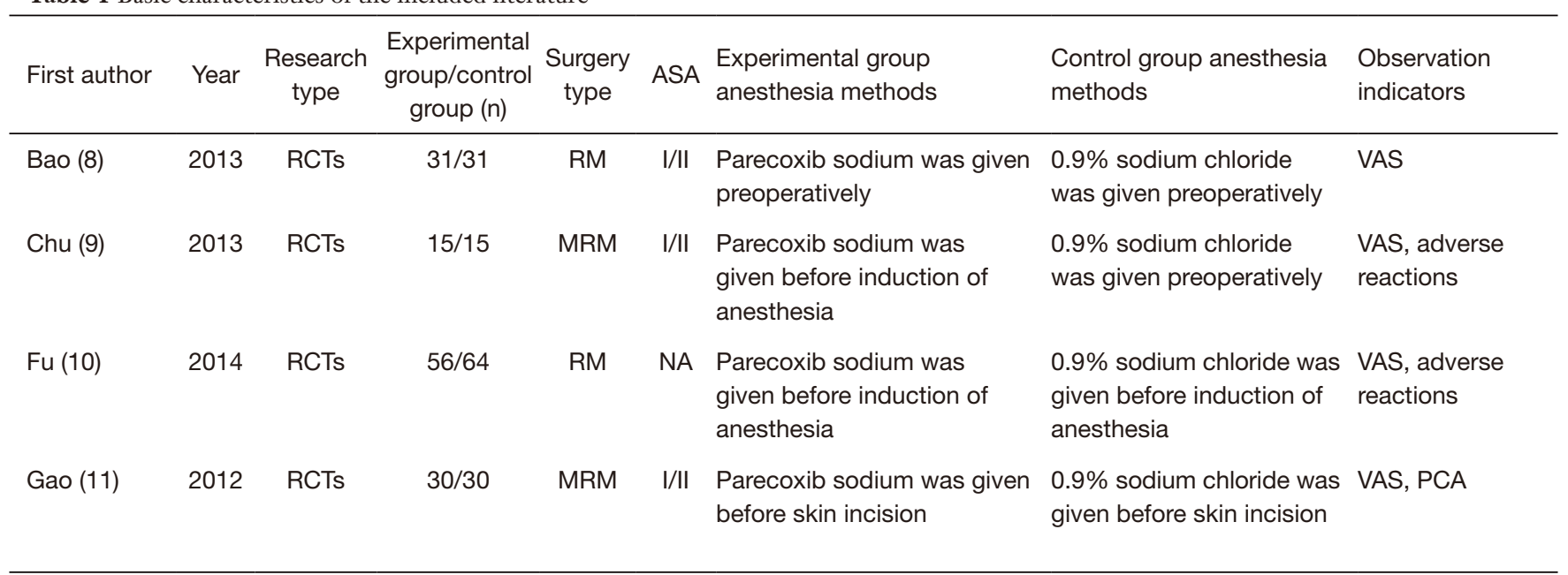

Table 1 (continued) 
Table 1 (continued)

\begin{tabular}{|c|c|c|c|c|c|c|c|c|}
\hline First author & Year & $\begin{array}{l}\text { Research } \\
\text { type }\end{array}$ & $\begin{array}{l}\text { Experimental } \\
\text { group/control } \\
\text { group }(n)\end{array}$ & $\begin{array}{l}\text { Surgery } \\
\text { type }\end{array}$ & ASA & $\begin{array}{l}\text { Experimental group } \\
\text { anesthesia methods }\end{array}$ & $\begin{array}{l}\text { Control group anesthesia } \\
\text { methods }\end{array}$ & $\begin{array}{l}\text { Observation } \\
\text { indicators }\end{array}$ \\
\hline Lai (13) & 2013 & RCTs & $20 / 20$ & $\mathrm{RM}$ & $I / I I$ & $\begin{array}{l}\text { Parecoxib sodium was given } \\
\text { preoperatively }\end{array}$ & $\begin{array}{l}\text { Tramadol was given } \\
\text { preoperatively }\end{array}$ & VAS \\
\hline Li (14) & 2010 & RCTs & $30 / 30$ & MRM & $I / I I$ & $\begin{array}{l}\text { Parecoxib sodium was given } \\
\text { postoperatively }\end{array}$ & $\begin{array}{l}0.9 \% \text { sodium chloride } \\
\text { was given postoperatively }\end{array}$ & $\begin{array}{l}\text { VAS, adverse } \\
\text { reactions }\end{array}$ \\
\hline Lyu (15) & 2017 & RCTs & $40 / 20$ & $\mathrm{RM}$ & NA & $\begin{array}{l}\text { Parecoxib sodium was given } \\
\text { preoperatively }\end{array}$ & $\begin{array}{l}0.9 \% \text { sodium chloride } \\
\text { was given preoperatively }\end{array}$ & $\begin{array}{l}\text { VAS, adverse } \\
\text { reactions, PCA }\end{array}$ \\
\hline Wang (18) & 2012 & RCTs & $20 / 20$ & $\mathrm{RM}$ & I/II & $\begin{array}{l}\text { Parecoxib sodium was } \\
\text { given before induction of } \\
\text { anesthesia }\end{array}$ & $\begin{array}{l}0.9 \% \text { sodium chloride was } \\
\text { given before induction of } \\
\text { anesthesia }\end{array}$ & $\begin{array}{l}\text { VAS, adverse } \\
\text { reactions, PCA }\end{array}$ \\
\hline Wu (19) & 2012 & RCTs & $20 / 20$ & $\mathrm{RM}$ & I/II & $\begin{array}{l}\text { Parecoxib sodium was given } \\
\text { preoperatively }\end{array}$ & $\begin{array}{l}0.9 \% \text { sodium chloride } \\
\text { was given preoperatively }\end{array}$ & VAS \\
\hline Wu (20) & 2019 & RCTs & $23 / 23$ & $\mathrm{RM}$ & I/II & $\begin{array}{l}\text { Parecoxib sodium and } \\
\text { oxycodone were given } \\
\text { postoperatively }\end{array}$ & $\begin{array}{l}\text { Oxycodone was given } \\
\text { postoperatively }\end{array}$ & VAS \\
\hline Yu (23) & 2014 & RCTs & $60 / 60$ & $\mathrm{RM}$ & I/II & $\begin{array}{l}\text { Parecoxib sodium and } \\
\text { ropivacaine were given } \\
\text { postoperatively }\end{array}$ & $\begin{array}{l}0.9 \% \text { sodium chloride } \\
\text { was given postoperatively }\end{array}$ & $\begin{array}{l}\text { VAS, adverse } \\
\text { reactions }\end{array}$ \\
\hline Zhang (24) & 2013 & RCTs & $30 / 30$ & $\mathrm{RM}$ & I/II & $\begin{array}{l}\text { Parecoxib sodium was } \\
\text { given preoperatively and } \\
\text { postoperatively }\end{array}$ & $\begin{array}{l}0.9 \% \text { sodium chloride } \\
\text { was given preoperatively } \\
\text { and postoperatively }\end{array}$ & VAS, PCA \\
\hline
\end{tabular}

ASA, American Association of Anesthesiologists; NA, surgery method was not mentioned; MRM, modified radical mastectomy; PCA, patient controlled analgesia; RCTs, randomized controlled trials; RM, radical mastectomy; VAS, visual analog scale.

\section{Quality assessment of the included literatures}

The Cochrane risk assessment form was adopted to evaluate the quality of the literature. As seen in Figures 2,3, none of these 17 studies had random sequence generation (selection bias), allocation concealment (selection bias), blinding of outcome assessment (detection bias), and incomplete outcome data (attrition bias). As Fu et al., Lyu et al., and Yang et al. $(10,15,21)$ did not elaborate on the ASA classification of patients in the included studies and the surgical treatment methods performed, the blinding 


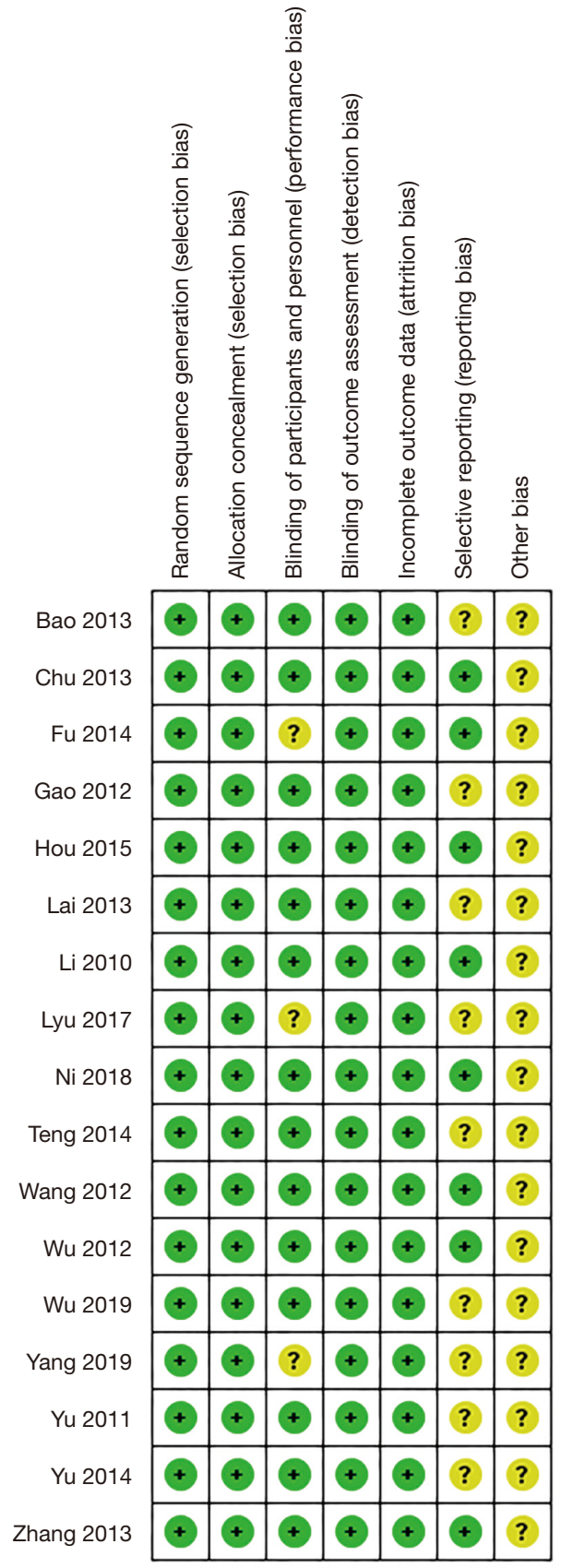

Figure 2 Bias risk diagram.

of participants and personnel (performance bias) was an "unclear" assessment result.

The Jadad Quality Assessment Scale was used to evaluate the quality of the literature. As seen in Table 2, the 17 studies were all randomized allocation trials, and there was no binding. After carefully reading the literature, none of the
17 studies mentioned hidden allocation, the withdrawal of personnel in the research process, and the specific reasons for the withdrawal in the middle of the research. According to the Jadad Quality Assessment Scale evaluation, the scores of these 17 studies were all within the range of 4-5, indicating that the literature was of good quality.

\section{Meta-analysis results}

\section{VAS score for postoperative analgesia in breast cancer patients}

The difference in VAS scores between groups $2 \mathrm{~h}$ after surgery was analyzed and compared. Figure 4 shows the results of the meta-analysis, the VAS scores of two groups at $2 \mathrm{~h}$ after surgery were heterogeneous $\left(\mathrm{I}^{2}=99 \%, \mathrm{P}<0.00001\right)$. After REM analysis, the combined result of the VAS score $2 \mathrm{~h}$ after surgery was MD: -0.79 and $95 \%$ CI: -1.29 to -0.29 . In addition, $Z=3.07$ and $P=0.002$, indicating that the VAS score of the experimental group was notably inferior to the control group $2 \mathrm{~h}$ after surgery $(\mathrm{P}<0.05)$.

The difference in VAS scores $4 \mathrm{~h}$ after surgery was analyzed and compared. Figure 5 shows the results of the meta-analysis, the VAS scores of two groups of patients at $4 \mathrm{~h}$ after surgery were heterogeneous $\left(\mathrm{I}^{2}=93 \%, \mathrm{P}<0.00001\right)$. After REM analysis, the combined result of the VAS score $4 \mathrm{~h}$ after surgery was $\mathrm{MD}:-0.77$ and $95 \% \mathrm{CI}:-1.51$ to -0.03 . In addition, the statistical significance test result was $\mathrm{Z}=2.05$ and $\mathrm{P}=0.04$, indicating that the VAS score of experimental patients was notably inferior to control group $4 \mathrm{~h}$ after surgery $(\mathrm{P}<0.05)$.

The difference in VAS scores at $6 \mathrm{~h}$ after surgery was analyzed and compared. Figure 6 shows that the VAS scores at $6 \mathrm{~h}$ after surgery were heterogeneous $\left(\mathrm{I}^{2}=92 \%\right.$, $\mathrm{P}<0.00001)$. After REM analysis, the combined result of VAS score $6 \mathrm{~h}$ after surgery was MD: -1.10 and $95 \%$ CI: -1.41 to -0.80 . In addition, $Z=7.10$ and $\mathrm{P}<0.00001$, indicating that the VAS score of the experimental group is significantly inferior to control group $6 \mathrm{~h}$ after surgery $(\mathrm{P}<0.05)$.

The difference in VAS scores $8 \mathrm{~h}$ after surgery was analyzed and compared. Figure 7 shows that VAS scores at $8 \mathrm{~h}$ after surgery were heterogeneous $\left(\mathrm{I}^{2}=95 \%\right.$, $\mathrm{P}<0.00001)$. After REM analysis, the combined result was MD: -0.66 and $95 \%$ CI: -1.00 to -0.33 . In addition, the statistical significance test result was $\mathrm{Z}=3.87$ and $\mathrm{P}=0.0001$, indicating that the VAS score of the experimental group was considerably inferior to control group $8 \mathrm{~h}$ after surgery $(\mathrm{P}<0.05)$. 


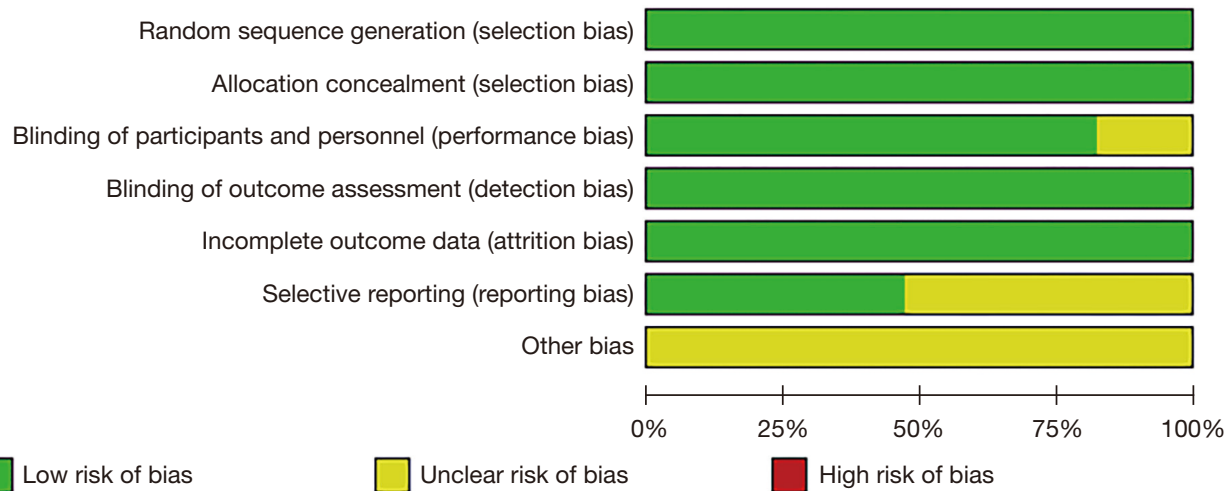

Figure 3 Risk bias of included literature.

Table 2 Jadad Quality Assessment Scale results of the included literatures

\begin{tabular}{|c|c|c|c|c|c|c|c|}
\hline First author & Year & Randomization & Binding & $\begin{array}{c}\text { Allocation } \\
\text { concealment }\end{array}$ & $\begin{array}{l}\text { Withdrawals and } \\
\text { dropouts }\end{array}$ & $\begin{array}{c}\text { Reason for dropout and } \\
\text { withdrawal }\end{array}$ & Jadad score \\
\hline Bao (8) & 2013 & Yes & No & - & - & No & 5 \\
\hline Chu (9) & 2013 & Yes & No & - & - & No & 5 \\
\hline $\mathrm{Fu}(10)$ & 2014 & Yes & No & - & - & No & 4 \\
\hline Lai (13) & 2013 & Yes & No & - & - & No & 4 \\
\hline $\mathrm{Li}(14)$ & 2010 & Yes & No & - & - & No & 4 \\
\hline Lyu (15) & 2017 & Yes & No & - & - & No & 4 \\
\hline Wu (19) & 2012 & Yes & No & - & - & No & 4 \\
\hline Wu (20) & 2019 & Yes & No & - & - & No & 4 \\
\hline Yang (21) & 2019 & Yes & No & - & - & No & 4 \\
\hline Yu (22) & 2011 & Yes & No & - & - & No & 4 \\
\hline Yu (23) & 2014 & Yes & No & - & - & No & 5 \\
\hline Zhang (24) & 2013 & Yes & No & - & - & No & 4 \\
\hline
\end{tabular}

- , not mentioned.

The difference in VAS scores $12 \mathrm{~h}$ after surgery was analyzed and compared. Figure 8 shows the results of the meta-analysis, the VAS scores at $12 \mathrm{~h}$ after surgery were heterogeneous $\left(\mathrm{I}^{2}=97 \%, \mathrm{P}<0.00001\right)$. After REM analysis, the combined result $12 \mathrm{~h}$ after surgery was MD: -0.92 and $95 \% \mathrm{CI}:-1.24$ to -0.60 . In addition, the statistical significance test result was $\mathrm{Z}=5.62$ and $\mathrm{P}<0.00001$, indicating that the VAS score of the experimental group is significantly inferior to control group $12 \mathrm{~h}$ after surgery $(\mathrm{P}<0.05)$.

The difference in VAS scores $24 \mathrm{~h}$ after surgery was analyzed and compared. Figure 9 shows the results of the 


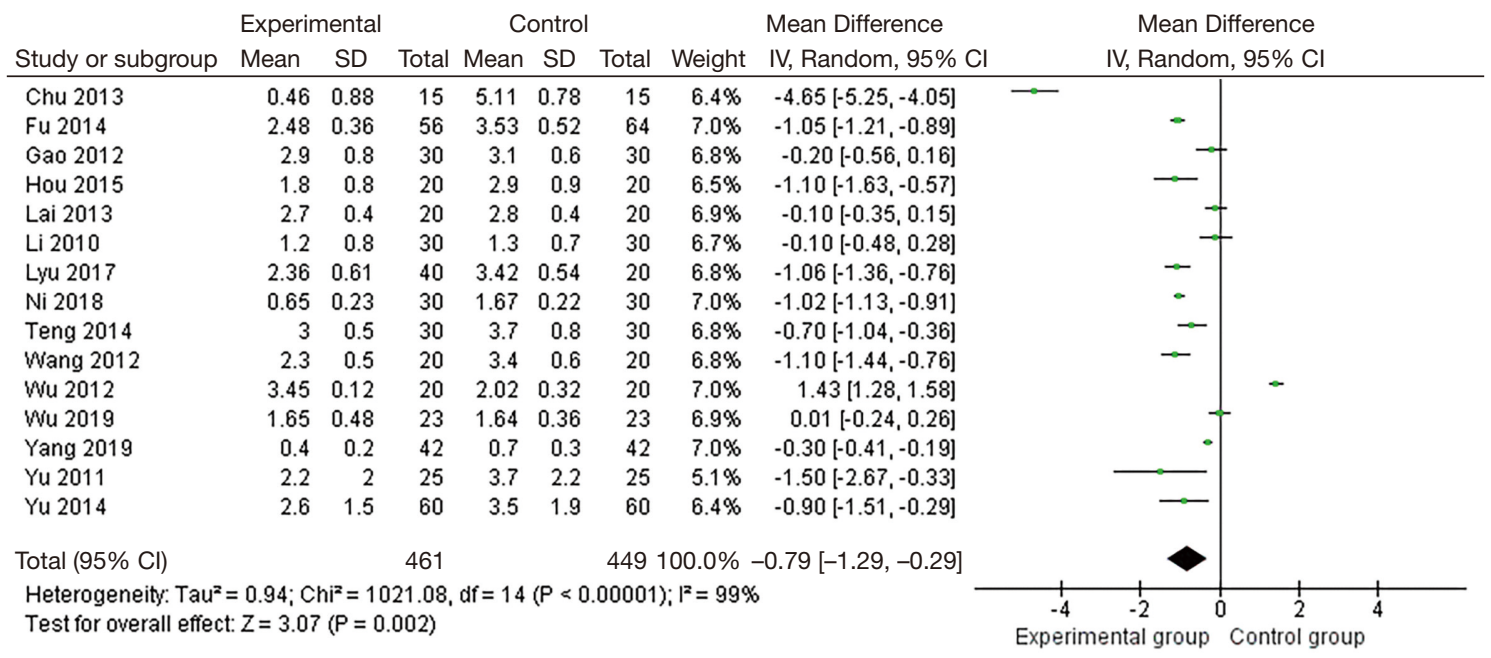

Figure 4 Visual analog scale scores 2 h after surgery. CI, confidence interval; IV, inverse variance methods; SD, standard deviation.

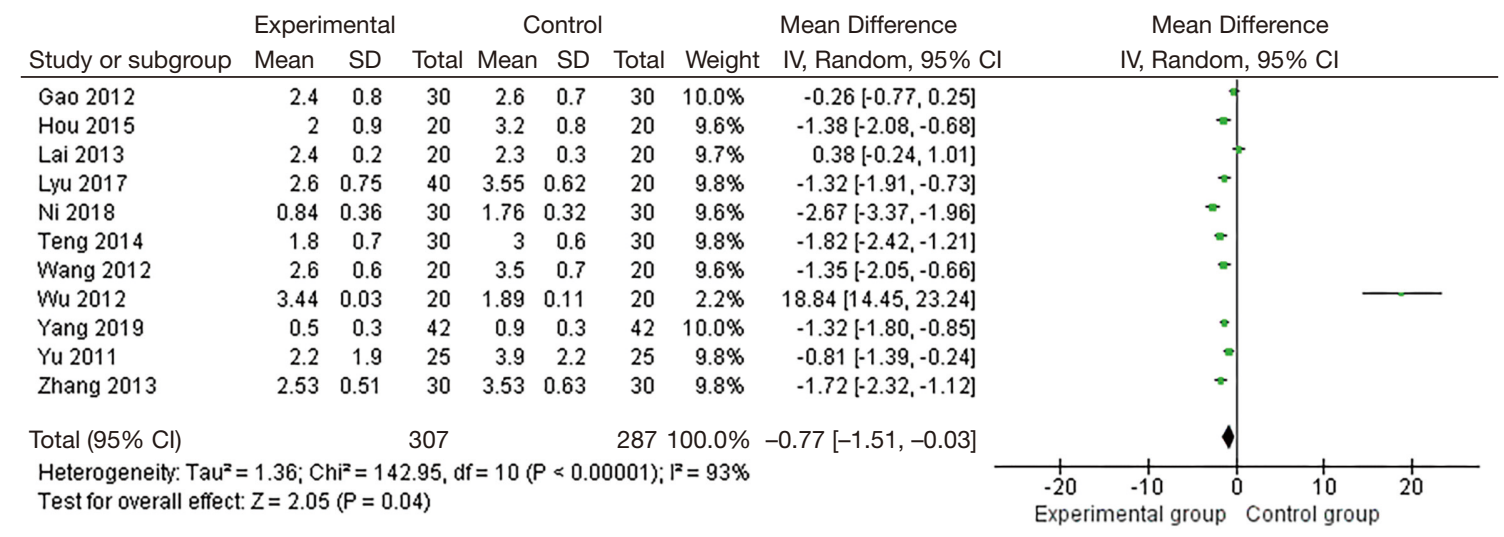

Figure 5 Visual analog scale scores 4 h after surgery. CI, confidence interval; IV, inverse variance methods; SD, standard deviation.

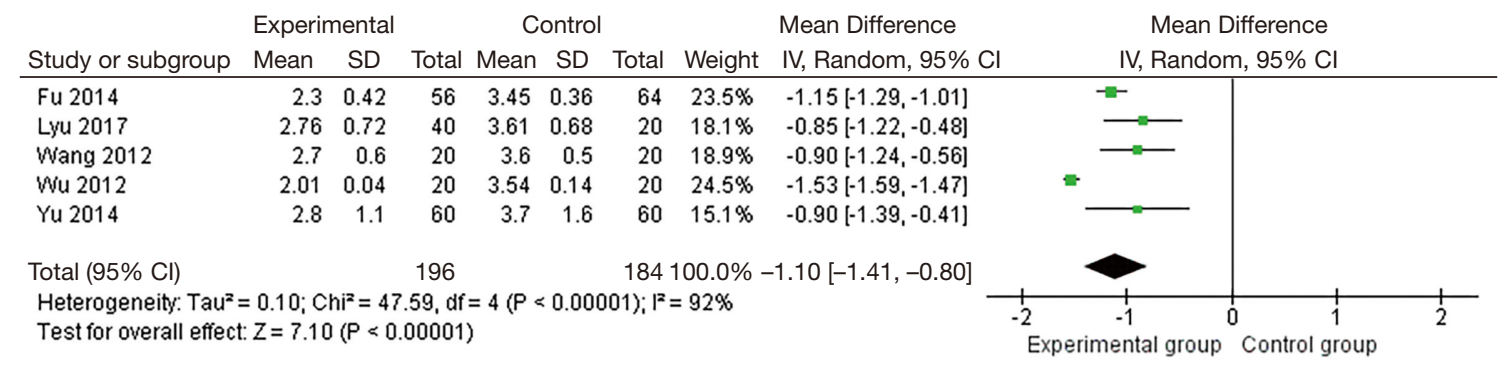

Figure 6 Visual analog scale scores 6 h after surgery. CI, confidence interval; IV, inverse variance methods; SD, standard deviation.

meta-analysis, the VAS scores of two groups at $24 \mathrm{~h}$ after surgery were heterogeneous $\left(\mathrm{I}^{2}=95 \%, \mathrm{P}<0.00001\right)$. After REM analysis, the combined result was MD: -0.86 and $95 \%$ CI: -1.15 to -0.58 . In addition, the statistical significance test result was $\mathrm{Z}=5.90$ and $\mathrm{P}<0.00001$, indicating that the VAS score of experimental patients was significantly inferior to control group $24 \mathrm{~h}$ after surgery $(\mathrm{P}<0.05)$.

The difference in VAS scores $48 \mathrm{~h}$ after surgery was 


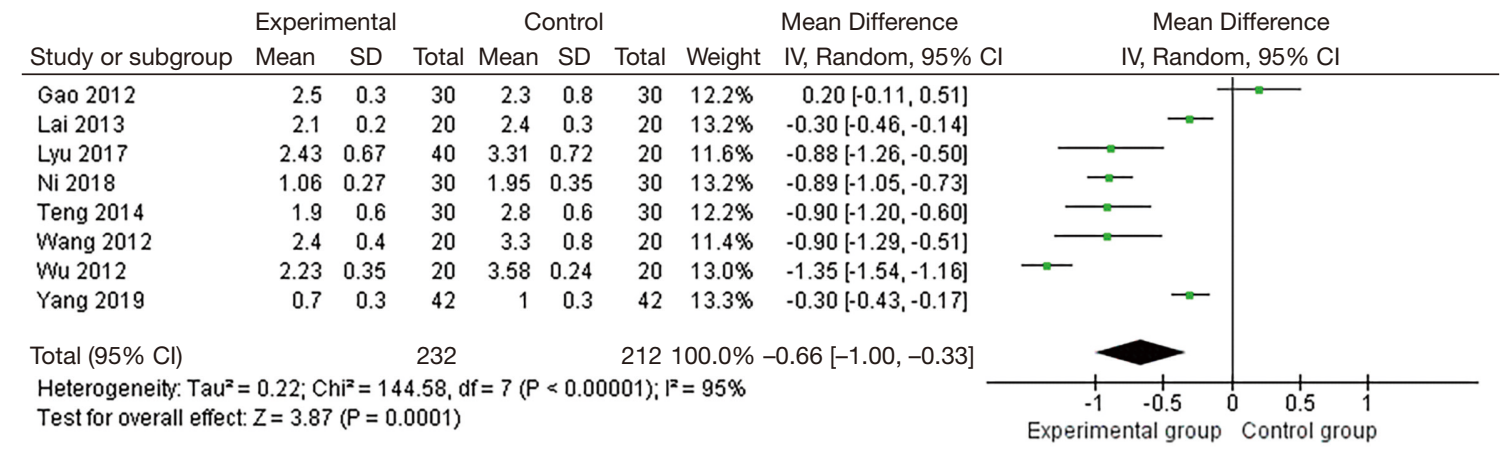

Figure 7 Visual analog scale scores 8 h after surgery. CI, confidence interval; IV, inverse variance methods; SD, standard deviation.

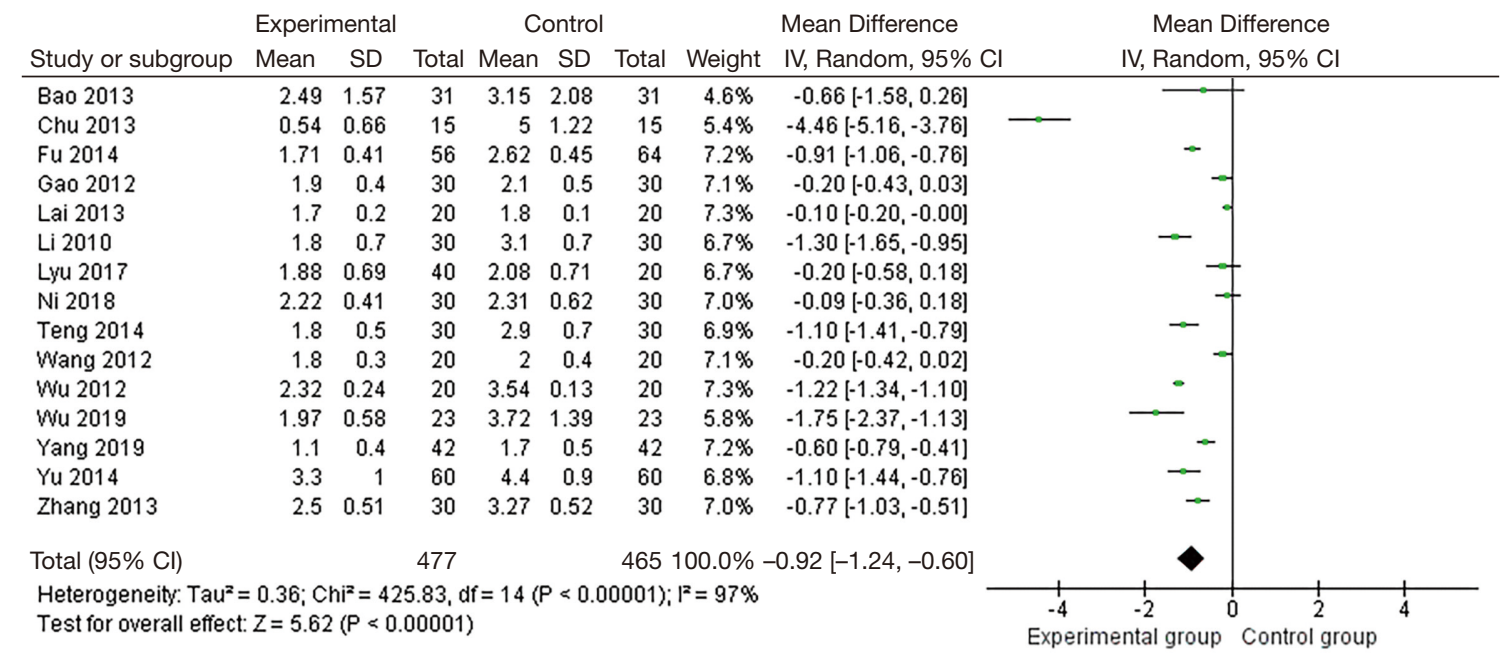

Figure 8 Visual analog scale scores 12 h after surgery. CI, confidence interval; IV, inverse variance methods; SD, standard deviation.

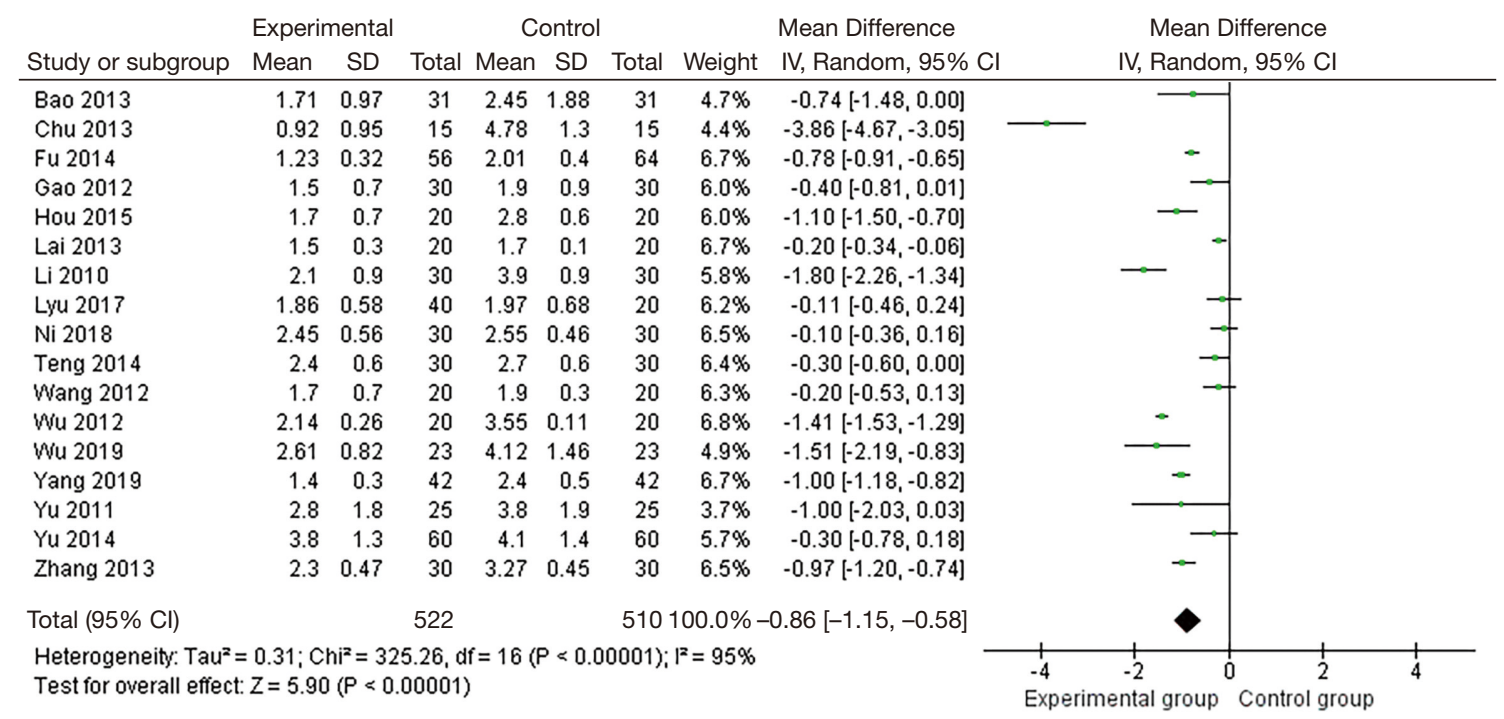

Figure 9 Visual analog scale scores 24 h after surgery. CI, confidence interval; IV, inverse variance methods; SD, standard deviation. 


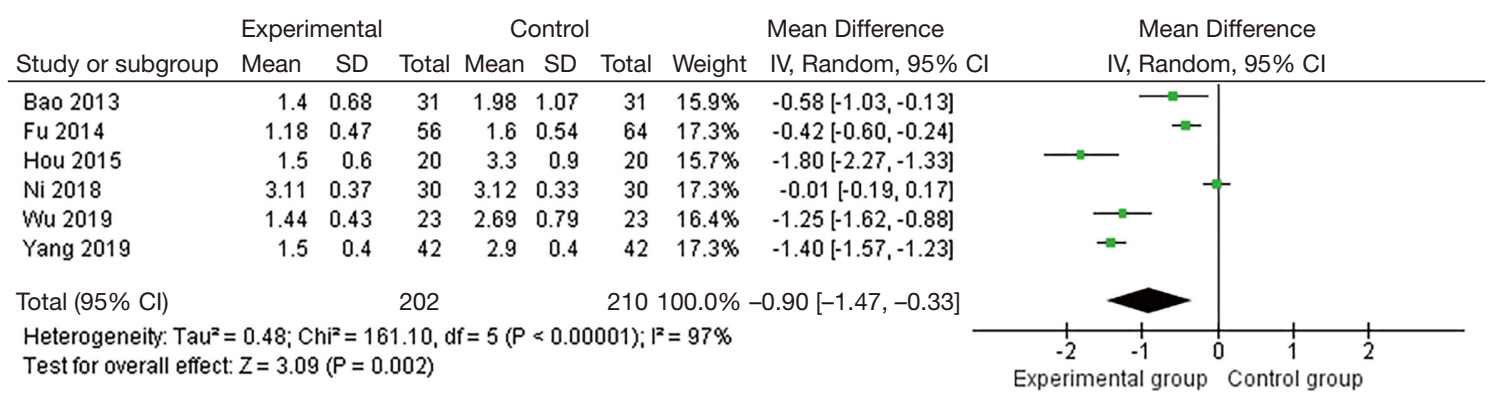

Figure 10 Visual analog scale scores $48 \mathrm{~h}$ after surgery. CI, confidence interval; IV, inverse variance methods; SD, standard deviation.

analyzed and compared. Figure 10 shows the results of the meta-analysis, the VAS scores $48 \mathrm{~h}$ after surgery were heterogeneous $\left(\mathrm{I}^{2}=97 \%, \mathrm{P}<0.00001\right)$. After REM analysis, the combined result was MD: -0.90 and $95 \% \mathrm{CI}:-1.47$ to -0.33 . In addition, the statistical significance test result was $Z=3.09$ and $P=0.002$, indicating that the VAS score of the experimental group is remarkably lower in contrast to control group $48 \mathrm{~h}$ after surgery $(\mathrm{P}<0.05)$.

Funnel plots were then used to conduct bias analysis of VAS scores at 2, 4, 6, 8, 12, 24, and $48 \mathrm{~h}$ after surgery, and the results are shown in Figure 11. As seen in Figure $11 A, 11 B, 11 D-11 G$, the funnel plots of VAS scores at $2,4,8,12,24$, and $48 \mathrm{~h}$ after surgery were basically symmetrical. Only a few samples did not fall into the funnel plot, indicating that the literature included had no significant risk of publication bias. As seen Figure 11C, the funnel plot of VAS score at $6 \mathrm{~h}$ after surgery was not symmetrical, indicating that there was a certain risk of publication bias in the included literature.

\section{Comparison of the number of postoperative PCA in breast cancer patients}

The frequency of PCA after surgery was analyzed and compared between the experimental group and control group. Figure 12 shows that the results of the metaanalysis, there was heterogeneity in the PCA frequency in two groups $\left(\mathrm{I}^{2}=85 \%, \mathrm{P}<0.0001\right)$. After REM analysis, the combined result of the meta-analysis effect value of the PCA frequency was MD: -2.08 and $95 \%$ CI: -2.88 to -1.27 . The statistical significance test result was $Z=5.07$ and $\mathrm{P}<0.00001$, indicating that PCA frequency in the experimental group was substantially lower compared with control group $(\mathrm{P}<0.05)$.

A qualitative evaluation of publication bias in the postoperative PCA frequency of patients included in the literature was implemented through a funnel chart analysis. As seen in Figure 13, the funnel chart of the PCA frequency of patients after surgery showed a symmetrical distribution, and only 1 study did not fall into the funnel chart, indicating that the literature had a low risk of publication bias.

\section{Comparison of postoperative adverse reaction rates in breast cancer patients}

The difference in the incidence of adverse reactions was compared. As shown in Figure 14, there was no heterogeneity in the incidence of adverse reactions $\left(\mathrm{I}^{2}=41 \%\right.$, $\mathrm{P}=0.10)$. After REM analysis, the combined result was OR: 0.52 and $95 \%$ CI: $0.34-0.80$. The statistical significance test result was $\mathrm{Z}=3.03$ and $\mathrm{P}=0.002$, indicating that the incidence of adverse reactions in the experimental group was relatively low $(\mathrm{P}<0.05)$.

As seen in Figure 15, the funnel chart of the incidence of postoperative adverse reactions was relatively symmetrical, and the research was relatively concentrated. Only 1 study did not fall into the funnel chart, indicating that the incidence of adverse reactions in patients had a low risk of publication bias among studies.

\section{Discussion}

With the progress of medical technology, the treatment effect of breast cancer has significantly improved, and the overall survival of many patients has increased. However, the treatment of sequelae affects the quality of life of patients to varying degrees. Postoperative breast cancer pain has unique characteristics and can become a chronic pain that affects the quality of life of patients for a prolonged period time, therefore, further research is warranted to solve this clinical problem. According to research, there are many drugs that are 

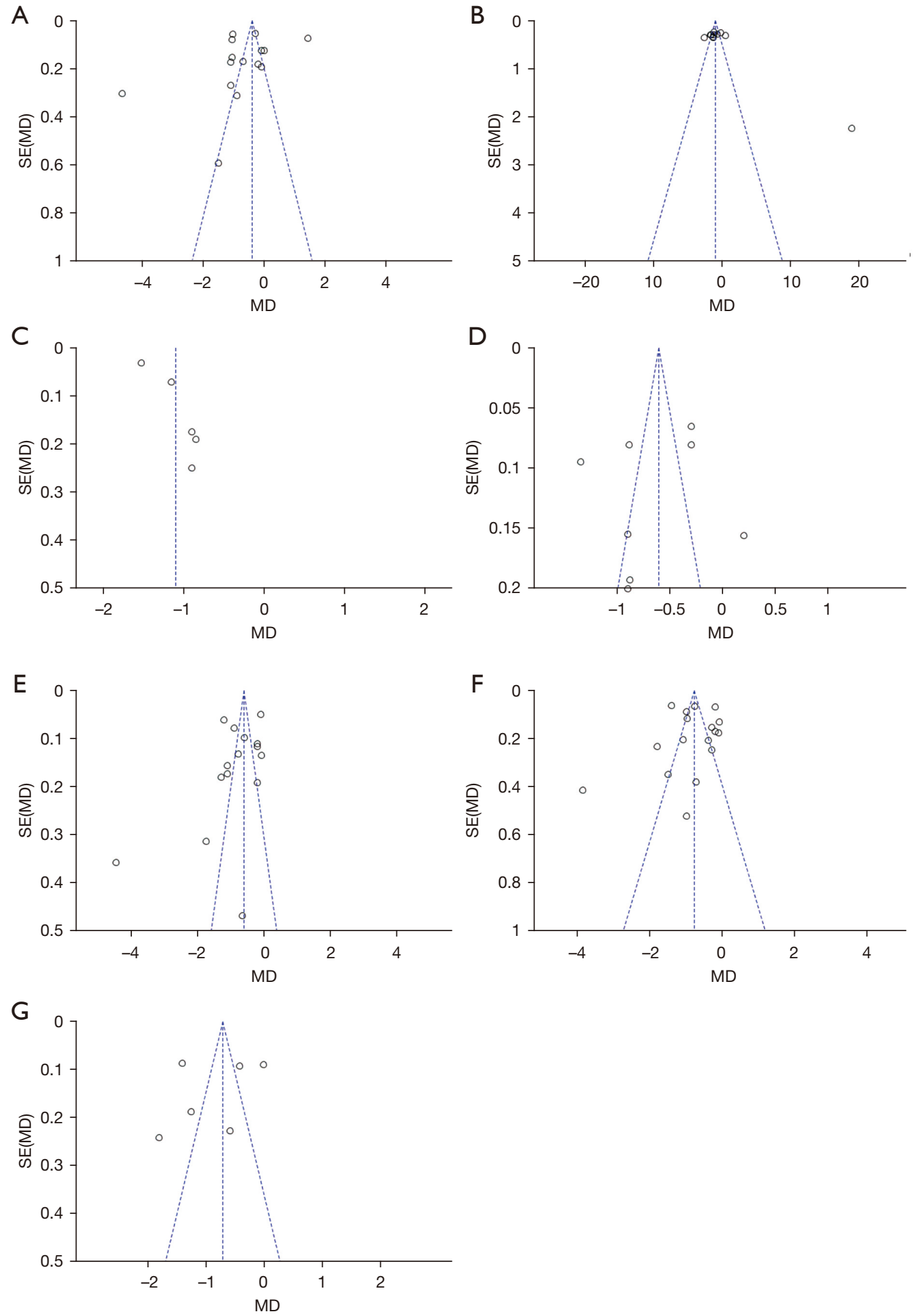

Figure 11 Publication bias funnel chart of visual analog scale (VAS) scores at different time points after surgery. (A) VAS score 2 h after surgery; (B) VAS score $4 \mathrm{~h}$ after surgery; (C) VAS score $6 \mathrm{~h}$ after surgery; (D) VAS score $8 \mathrm{~h}$ after surgery; (E) VAS score $12 \mathrm{~h}$ after surgery; (F) VAS score $24 \mathrm{~h}$ after surgery; (G) VAS score $48 \mathrm{~h}$ after surgery. MD, mean difference; SE, standard error. 


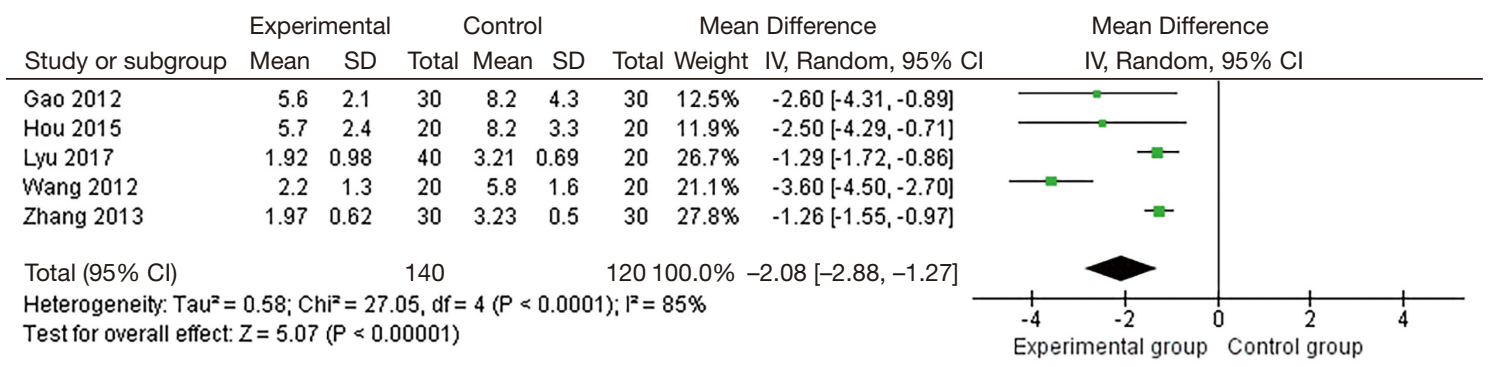

Figure 12 PCA frequency of patients after surgery. PCA, patient controlled analgesia; CI, confidence interval; IV, inverse variance methods; $\mathrm{SD}$, standard deviation.

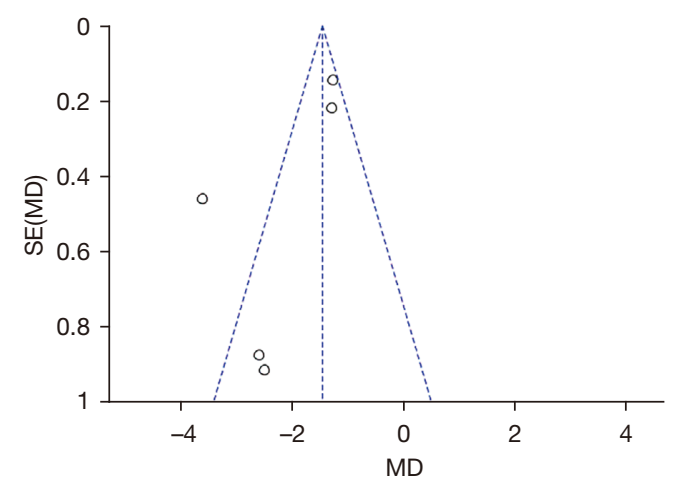

Figure 13 Publication bias funnel chart of the number of postoperative PCA of patients. MD, mean difference; SE, standard error; PCA, patient controlled analgesia.

used to treat the postoperative pain of breast cancer (25). The pre-administration of tramadol before radical mastectomy of breast cancer has been found to produce a good analgesic effect (26). Pregabalin combined with etoricoxib has a good analgesic effect, which can be used in the treatment of patients with pain after radical treatment of breast cancer, with few adverse reactions (27). Dexmedetomidine is a selective $\alpha_{2}$ adrenergic receptor agonist, and sufentanil is a potent fat-soluble narcotic analgesic. Both the drugs have sedative, analgesic and anti-anxiety effects $(28,29)$. Parecoxib sodium can effectively inhibit the synthesis and release of prostaglandins, thereby inhibiting hyperalgesia and increasing pain threshold (30). Compared with dexmedetomidine and sufentanil, parecoxib sodium has a more obvious therapeutic effect on the agitation caused by pain. However, parecoxib sodium only has analgesic effects, but lacks sedative and anti-anxiety effects (31). The advanced application of parecoxib sodium in gynecological surgery can reduce the amount of postoperative fentanyl and improve the quality of analgesia (32). Therefore, the effect of parecoxib sodium in the treatment of postoperative pain in patients undergoing breast cancer surgery was comprehensively assessed in this systematic review.

Perioperative analgesia is one of the main clinical problems that surgeons face, and continuous pain stimulation can cause pathological remodeling of the central nervous system. In severe cases, it may lead to chronic painful diseases that are difficult to control (33). Many studies have suggested that the use of parecoxib sodium in clinical orthopedics, general surgery, and neurosurgery operations can significantly reduce the incidence of postoperative pain and adverse reactions in patients (34). To evaluate the effect of parecoxib sodium in the treatment of postoperative pain in patients undergoing breast cancer surgery, we included 17 randomized controlled trials of parecoxib sodium in the treatment of breast cancer patients. After meta-analysis, the results showed that the VAS scores of 2, 4, 6, 8, 12, 24, and $48 \mathrm{~h}$ after surgery for breast cancer patients treated with parecoxib sodium were significantly reduced, as was PCA frequency after surgery, indicating that parecoxib sodium can improve the postoperative pain effect of breast cancer patients and reduce pain. In addition, it was found that parecoxib sodium treatment of breast cancer patients has a significantly reduced probability of adverse reactions after surgery, indicating that parecoxib sodium can reduce the incidence of adverse reactions in breast cancer patients after surgery, and is of high safety in clinical adoption.

It is clinically recommended that parecoxib sodium should not be used continuously for more than 3 days, and high-dose parecoxib sodium can increase the incidence of adverse reactions (35). Due to the high risk, the patient is not able to inject parecoxib sodium by himself after being discharged from the hospital. Pain is the most common symptom of patients at home, so it is especially important 


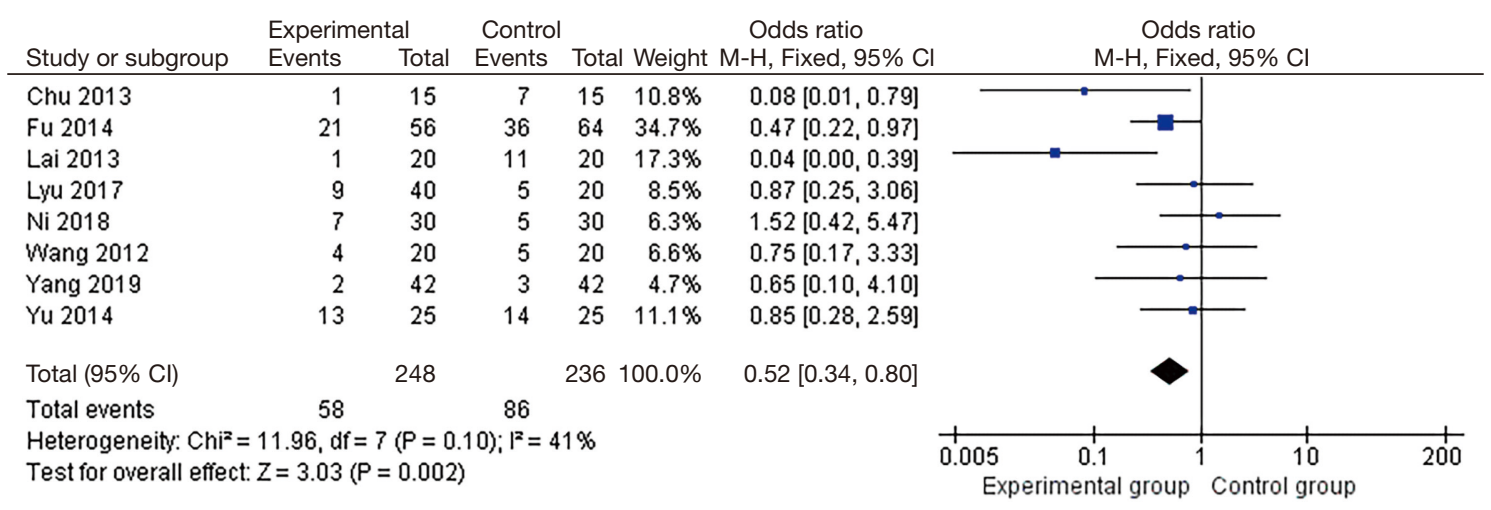

Figure 14 Incidence of adverse reactions in patients after surgery. CI, confidence interval; IV, inverse variance methods; SD, standard deviation.

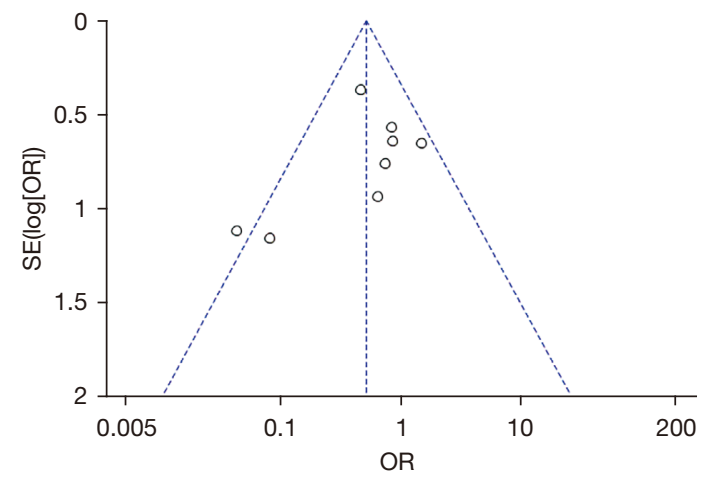

Figure 15 Publication bias funnel chart of the incidence of postoperative adverse reactions in patients. OR, odds ratio; SE, standard error.

to integrate appropriate methods to relieve pain after discharge. The easiest way is to take analgesics by mouth (different drugs, different dosages and different frequency of use), but this requires a high degree of patient compliance. Studies have found that some non-traditional methods used in the hospital can provide good pain relief after discharge, including intranasal, mucosal and transdermal analgesics, and nerve electrical stimulation therapy (36). Therefore, it is recommended to give analgesics after the operation, and cooperate with nerve electrical stimulation therapy, etc.

\section{Conclusions}

Parecoxib sodium can reduce the VAS score, PCA frequency, and adverse reaction rate of postoperative pain in breast cancer patients. In addition, parecoxib sodium local anesthesia for breast cancer surgery patients has excellent analgesic effect and safety. However, the present study has some limitations. For example, many drugs have a similar effect as parecoxib sodium, but are not discussed. Therefore, future work will focus on the effect of combinations of multiple drugs on the effect of postoperative pain in patients undergoing breast cancer surgery. The results of the present study provide evidence that support the promotion and adoption of parecoxib sodium in clinical practice.

\section{Acknowledgments}

Funding: None.

\section{Footnote}

Reporting Checklist: The authors have completed the PRISMA reporting checklist. Available at https://dx.doi. org/10.21037/gs-21-632

Conflicts of Interest: All authors have completed the ICMJE uniform disclosure form (available at https://dx.doi. org/10.21037/gs-21-632). The authors have no conflicts of interest to declare.

Ethical Statement: The authors are accountable for all aspects of the work in ensuring that questions related to the accuracy or integrity of any part of the work are appropriately investigated and resolved.

Open Access Statement: This is an Open Access article distributed in accordance with the Creative Commons 
Attribution-NonCommercial-NoDerivs 4.0 International License (CC BY-NC-ND 4.0), which permits the noncommercial replication and distribution of the article with the strict proviso that no changes or edits are made and the original work is properly cited (including links to both the formal publication through the relevant DOI and the license). See: https://creativecommons.org/licenses/by-nc-nd/4.0/.

\section{References}

1. Lu J, Chen Y, Hu M, Sun C. Clinical efficacy of arthroscopy in the treatment of discoid meniscus injury and related risk factors for postoperative pain. Ann Palliat Med 2020;9:4002-9.

2. Cheung CW, Ching Wong SS, Qiu Q, et al. Oral Oxycodone for Acute Postoperative Pain: A Review of Clinical Trials. Pain Physician 2017;20:SE33-52.

3. Hollmann MW, Rathmell JP, Lirk P. Optimal postoperative pain management: redefining the role for opioids. Lancet 2019;393:1483-5.

4. Bian YY, Wang LC, Qian WW, et al. Role of Parecoxib Sodium in the Multimodal Analgesia after Total Knee Arthroplasty: A Randomized Double-blinded Controlled Trial. Orthop Surg 2018;10:321-7.

5. Zhuang Q, Tao L, Lin J, et al. Postoperative intravenous parecoxib sodium followed by oral celecoxib post total knee arthroplasty in osteoarthritis patients (PIPFORCE): a multicentre, double-blind, randomised, placebo-controlled trial. BMJ Open 2020;10:e030501.

6. Huang Z, Ma X, Jia X, et al. Prevention of Severe Acute Pancreatitis With Cyclooxygenase-2 Inhibitors: A Randomized Controlled Clinical Trial. Am J Gastroenterol 2020;115:473-80.

7. Wang RD, Zhu JY, Zhu Y, et al. Perioperative analgesia with parecoxib sodium improves postoperative pain and immune function in patients undergoing hepatectomy for hepatocellular carcinoma. J Eval Clin Pract 2020;26:992-1000.

8. Bao SL. The effect of preoperative application of parecoxib on breast cancer patients with postoperative pain. Henan Journal of Surgery 2013;19:5-6.

9. Chu XY, Xia YM, Zhang FJ, et al. Effects of parecoxib sodium on analgesia after radical mastectomy for breast cancer. Journal of Shanghai Jiaotong University (Medical Science) 2013;33:196-9.

10. Fu K. Clinical efficacy of preemptive analgesia with combination use of parecoxib sodium and dezocine in radical mastectomy. Chinese Journal of General Surgery
2014;23:1543-7.

11. Gao S, Tian WH, Li JJ, et al. Effect of parecoxib sodium of different delivery ways on modified radical mastectomy of breast cancer patients postoperative morphine consumption. Modern Medical Journal 2012;40:420-3.

12. Hou YS, Liu YT, Khan NG. Effect of preemptive analgesia with parecoxib sodium on postoperative acute and chronic pain in patients with modified radical mastectomy. Xinjiang Medical Journal 2015;45:337-9.

13. Lai XH, Yang CX, Liu HZ, et al. Effects of parecoxib sodium on the immune function of patients undergoing breast cancer radical mastectomy during the perioperative period. China Journal of Modern Medicine 2013;23:79-82.

14. Li B, Li JH, Hu HY, et al. Influence of parecoxib on analgesic effect and stress response in patients after radical excision of breast cancer. Chin J Breast Dis (Electronic Edition) 2010;4:144-8.

15. Lyu DH, Wang ZY, Zhang TJ, et al. Effects Observation of Preemptive Analgesia of Parecoxib-sodium for Radical Mastectomy of Breast Cancer. China Pharmacy 2017;28:2506-8.

16. Ni YH, Han MJ, Xie YB, et al. Effect of parecoxib sodium combined with ropivacaine on postoperative pain in patients with breast cancer. Journal of Minimally Invasive Medicine 2018;23:458-60, 484.

17. Teng PL, Xu DR, Yang J, et al. Effects of preoperative parecoxib on interleukin and postoperative analgesia for mastectomy. J Clin Anesthesiol 2014;30:1221-2.

18. Wang B, Qing ZH, Lu Y, et al. Effects of parecoxib for preemptive analgesia on fentanyl-induced patientcontrolled analgesia following radical mastectomy. Academic Journal of Guangzhou Medical College 2012;40:60-2.

19. Wu Y, Li ZJ, Fu QY, et al. Influence of preemptive parecoxib on platelet function and blood coagulation function in patients of radical excision of breast cancer. Chin J Clinicians (Electronic Edition) 2012;6:61-3.

20. Wu WY, Zhang YX, Liu ZL. The influence of parecoxib sodium combined with oxycodone on analgesic effect and stress response in patients with breast cancer. Journal of Qiqihar Medical University 2019;40:437-9.

21. Yang YG. Observation of the analgesic effect of ropivacaine combined with parecoxib sodium after breast cancer surgery. Capital Food Medicine 2019;26:77.

22. Yu DP, Cao MY, Zhu HC. Effect of preemptive analgesia with parecoxib sodium on cardiovascular response and postoperative pain in patients undergoing radical 
mastectomy. Guangdong Medical Journal 2011;32:315-7.

23. Yu S. Preemptive analgesia effect of parecoxib sodium on postoperative analgesia in patients undergoing radical mastectomy. Medical Aesthetics and Cosmetology 2014;6:104.

24. Zhang WM, Wang PD, Lei $W$, et al. The preemptive analgesia of parecoxib sodium on postoperative pain after breast cancer surgery. Journal of Clinical and Experimental Medicine 2013;12:1012-4.

25. Rai AS, Khan JS, Dhaliwal J, et al. Preoperative pregabalin or gabapentin for acute and chronic postoperative pain among patients undergoing breast cancer surgery: A systematic review and meta-analysis of randomized controlled trials. J Plast Reconstr Aesthet Surg 2017;70:1317-28.

26. Kim MH, Oh JE, Park S, et al. Tramadol use is associated with enhanced postoperative outcomes in breast cancer patients: a retrospective clinical study with in vitro confirmation. Br J Anaesth 2019;123:865-76.

27. Khan JS, Hodgson N, Choi S, et al. Perioperative Pregabalin and Intraoperative Lidocaine Infusion to Reduce Persistent Neuropathic Pain After Breast Cancer Surgery: A Multicenter, Factorial, Randomized, Controlled Pilot Trial. J Pain 2019;20:980-93.

28. Barends CR, Absalom A, van Minnen B, et al. Dexmedetomidine versus Midazolam in Procedural Sedation. A Systematic Review of Efficacy and Safety. PLoS One 2017;12:e0169525.

29. Yang HF, Yu M, Jin HD, et al. Fentanyl Promotes Breast Cancer Cell Stemness and Epithelial-Mesenchymal Transition by Upregulating $\alpha 1$, 6-Fucosylation via Wnt/ $\beta$-Catenin Signaling Pathway. Front Physiol 2017;8:510.

Cite this article as: Chen F, Fan Y, Zhu S. Postoperative analgesic effect of parecoxib sodium local anesthesia in patients with breast cancer through systematic review and meta-analysis. Gland Surg 2021;10(11):3082-3096. doi: 10.21037/gs-21-632
30. Wang YC, Yu WZ. Prospective study on the effect of parecoxib sodium analgesia on pain and stress response after surgery in elderly patients with hip fracture. Zhongguo Gu Shang 2021;34:612-6.

31. Hu J, Lv BF, Guo WJ, et al. Effects of Dexmedetomidine on the Pharmacokinetics of Parecoxib and Its Metabolite Valdecoxib in Beagles by UPLC-MS/MS. Biomed Res Int 2020;2020:1563874.

32. Li Y, Zhou L, Li X, et al. Parecoxib suppresses the increase of neutrophil-to-lymphocyte ratio after the modified radical mastectomy. Zhong Nan Da Xue Xue Bao Yi Xue Ban 2017;42:1048-52.

33. Comparin D, Moreira EJL, Souza EM, et al. Postoperative Pain after Endodontic Retreatment Using Rotary or Reciprocating Instruments: A Randomized Clinical Trial. J Endod 2017;43:1084-8.

34. Xiao K, Yu L, Xiao W, et al. Pain Management Using Perioperative Administration of Parecoxib for Total Hip Arthroplasty: A Randomized, Double-Blind, PlaceboControlled Trial. Pain Physician 2019;22:575-82.

35. Schug SA, Parsons B, Li C, et al. The safety profile of parecoxib for the treatment of postoperative pain: a pooled analysis of 28 randomized, double-blind, placebocontrolled clinical trials and a review of over 10 years of postauthorization data. J Pain Res 2017;10:2451-9.

36. Santana LS, Gallo RB, Ferreira CH, et al. Transcutaneous electrical nerve stimulation (TENS) reduces pain and postpones the need for pharmacological analgesia during labour: a randomised trial. J Physiother 2016;62:29-34.

(English Language Editor: R. Scott) 